\title{
The effect of curing intensity on mechanical properties of different bulk-fill composite resins
}

This article was published in the following Dove Press journal:

Clinical, Cosmetic and Investigational Dentistry

23 February 2017

Number of times this article has been viewed

\author{
Fahad I Alkhudhairy \\ Restorative Dental Sciences \\ Department, College of Dentistry, \\ King Saud University, Riyadh, Kingdom \\ of Saudi Arabia
}

Objective: The purpose of this study was to investigate the effects of two curing light intensities on the mechanical properties (Vickers microhardness, compressive strength, and diametral tensile strength) of bulk-fill resin-based composites (RBCs).

Materials and methods: Four commercially available bulk-fill RBCs (Tetric ${ }^{\circledR} \mathrm{N}-C e r a m$, SonicFill $^{\mathrm{TM}}$, Smart Dentin Replacement (SDR ${ }^{\mathrm{TM}}$ ) Posterior Flowable Material, and Filtek ${ }^{\mathrm{TM}}$ Posterior Restorative) were used in this study. A total of 72 cylindrical specimens of each RBC $(n=288)$ were prepared and subjected to Vickers microhardness, compressive strength, and diametral tensile strength tests at high $\left(1200 \mathrm{~mW} / \mathrm{cm}^{2}\right)$ and low $\left(650 \mathrm{~mW} / \mathrm{cm}^{2}\right)$ curing light intensities (each $\mathrm{n}=12$ ). Results were evaluated using independent and paired sample $t$-tests, one-way analysis of variance, and Tukey's post hoc test. All tests were performed at a significance level of $P<0.05$. Results: The highest mean microhardness was observed for SonicFill (58.3 Vickers hardness number $[\mathrm{VHN}]$ ) cured using high-intensity light. Although having the least mean microhardness values, a significant difference was observed between SDR cured using high-intensity light and that cured using low-intensity light $(P<0.05)$. In the total sample, the highest mean compressive strength was obtained for SonicFill (262.6 MPa), followed by SDR (253.2 MPa), both cured using high-intensity light, and the least was measured for Tetric N-Ceram cured using lowintensity light (214.3 MPa). At high and low curing light intensities, diametral tensile strength for all RBCs except SonicFill was significant $(P<0.001)$.

Conclusion: A higher curing light intensity $\left(1200 \mathrm{~mW} / \mathrm{cm}^{2}\right)$ had a positive influence on the compressive and tensile strength of the four bulk-fill RBCs and microhardness of two materials tested compared with lower curing light intensity $\left(650 \mathrm{~mW} / \mathrm{cm}^{2}\right)$. SonicFill showed the greatest microhardness and compressive strength significantly for both curing light intensities and greater diametral tensile strength with high-intensity light, although not significant. SDR cured with high-intensity light showed the greatest diametral tensile strength among the four materials.

Keywords: resin-based composites, bulk-fill, microhardness, compressive strength, diametral tensile strength

\section{Introduction}

Direct restorations are preferred in restorative dentistry. With the evolution of resinbased composite (RBC) materials, dental amalgam is no longer preferred for posterior restorations. Composite restorations have good esthetic and mechanical properties, as well as bonding strength to the tooth structure, and are thereby accepted as reliable materials for direct anterior and posterior restorations. ${ }^{1}$ However, the use of photopolymerizable composite restorative materials requires the performance of sensitive technical procedures, such as complete isolation, multiple methodical layering, and
Correspondence: Fahad I Alkhudhairy Restorative Dental Sciences Department, College of Dentistry, King Saud University, PO Box 60169, Riyadh II545, Kingdom of Saudi Arabia

Email Dr_fahad9@outlook.com 
adequate curing. Bulk-fill RBCs have minimized the need for these time-consuming procedures. ${ }^{1,2}$ They enable restoration in thick (up to $4 \mathrm{~mm}$ ) layers with adequate curing throughout the bulk of the restoration, reducing the time requirement and thereby improving patient compliance; they are thus the material of choice in current dental clinical practice. ${ }^{3}$ Despite their advantages, however, few studies have assessed the physical and mechanical properties of bulk-fill RBC restorations. ${ }^{46}$

Curing light intensity is a key factor in the use of photopolymerizable composites, and the achievement of complete curing is challenging in clinical practice. Bulk-fill composites are translucent resins that can be cured adequately in thick layers, with suitable mechanical properties and a low degree of polymerization shrinkage. ${ }^{7}$ Adequate polymerization requires a light-emitting diode (LED) intensity of 400$500 \mathrm{~mW} / \mathrm{cm}^{2}$. To achieve consistent polymerization of RBCs, an intensity of $200-600 \mathrm{~mW} / \mathrm{cm}^{2}$ with adequate exposure time is considered to be satisfactory. ${ }^{8}$ Improved LEDs, which have a higher range of intensity $\left(500-1400 \mathrm{~mW} / \mathrm{cm}^{2}\right)$, cover a broader portion of the visible blue light spectrum. ${ }^{9}$ Spectral analysis has shown that LEDs emit larger amounts of light in the area of $470 \mathrm{~nm}$. Brandt et $\mathrm{al}^{10}$ reported irradiance values of $78.1 \%$ and $83.8 \%$ for the Ultra Blue IS $\left(466.3-597 \mathrm{~mW} / \mathrm{cm}^{2}\right)$ and Ultra Lume $5\left(1102-1315 \mathrm{~mW} / \mathrm{cm}^{2}\right)$ light-curing units, respectively, indicating that they emit greater amounts of light in the area of $470 \mathrm{~nm}$ by allowing the desired degree of conversion.

The newest class of bulk-fill RBCs includes flowable and higher viscosity pastes, which practitioners favor because of their simplified usage. Newer materials (e.g., Venus Bulk Fill, Tetric EvoCeram Bulk-Fill RBC, SureFil Smart Dentin Replacement [SDR ${ }^{\mathrm{TM}}$ ] Flow Flowable Base RBC, X-tra base hybrid RBC, X-tra fil hybrid RBC, SonicFill ${ }^{\mathrm{TM}}$ Nanohybrid RBC, Filtek ${ }^{\mathrm{TM}}$ Bulk Fill nano RBC, and Xenius and Coltene Dual-Cure Bulk-Fill RBCs) have demonstrated excellent mechanical properties. ${ }^{11,12}$ However, the mechanical properties of bulk-fill composites, particularly paste, flowable, and dual-cure RBCs, have proven to be less satisfactory than those of nanohybrid and microhybrid RBCs. ${ }^{13}$ The mechanical performance of bulk-fill RBCs has been characterized using the Vickers microhardness (VMH) test and the evaluation of properties such as compressive strength (CS), diametral tensile strength (DTS), flexure modulus, indentation modulus, and creep. Dissatisfactory mechanical performance reduces long-term stability, which has become a major concern for dental practitioners, researchers, and product developers. ${ }^{14}$

The purpose of this study was to investigate the effects of two light-curing intensities on the mechanical properties
(CS, VMH, and DTS) of bulk-fill RBCs. The identification of a suitable curing intensity could improve the mechanical performance of these materials. Thus, the hypothesis tested was that the higher the curing light intensity used, the higher will be the mechanical properties of the composite materials tested.

\section{Materials and methods Specimen preparation and curing}

Four commercially available bulk-fill RBCs (Tetric ${ }^{\circledR} \mathrm{N}$-Ceram Bulk Fill [Ivoclar Vivadent, Amherst, NY, USA]; SonicFill [Kerr Corporation, Orange, CA, USA]; SDR Posterior Bulk Fill Flowable Material [Dentsply Caulk, Milford, DE, USA]; Filtek Bulk Fill Posterior Restorative [3M ESPE, St. Paul, MN, USA]) were used in this study as presented in Table 1. A total of 96 cylindrical specimens of each RBC (total, $\mathrm{n}=288$ ) were prepared and subjected to VMH, CS, and DTS testing at two light intensities (each $\mathrm{n}=12$ ).

A two-part brass mold with a diameter of $5 \mathrm{~mm}$ and a thickness of $4 \mathrm{~mm}$ was used to prepare the specimens according to the manufacturer's recommendations. For each specimen, a clear Mylar strip (Dentsply Caulk) was placed on top of a clean glass slab, and the mold was placed on top of the strip. The RBC was then packed into the mold using plastic and condensed. The upper surface of the composite was covered with a clear Mylar strip and a $1 \mathrm{~mm}$-thick glass slide was placed on top of it and pressed gently to obtain a flat surface. The Mylar strips were placed on the top and bottom composite surfaces during curing to ensure smoothness and prevent the formation of an oxygen-inhibited area. The specimens were light cured using an LED unit (Bluephase $\mathrm{N}^{\circledR}$; Ivoclar Vivadent, Schaan, Liechtenstein) for 20 seconds at $1200 \mathrm{~mW} / \mathrm{cm}^{2}$ (high curing light intensity) or $650 \mathrm{~mW} / \mathrm{cm}^{2}$ (low curing light intensity) consisting of 48 specimens for each curing light intensity. Power intensity was measured using a dental radiometer (Bluephase ${ }^{\circledR}$ meter; Ivoclar Vivadent, Schaan, Liechtenstein). After careful removal from the mold, the 12 specimens in each subgroup were stored in a light-proof container with distilled water and incubated (Memmert, Schwabach, Germany) at $37^{\circ} \mathrm{C}$ for $24 \mathrm{~h}$. After storage, the specimens were aged with a thermocycler (SD Mechatronik GmbH, Feldkirchen-Westerham, Germany) for 1500 cycles at $5^{\circ} \mathrm{C}$ and $55^{\circ} \mathrm{C}$ with a dripping time of 10 seconds.

\section{$\mathrm{VMH}$ test}

Immediately after aging, each of the 96 specimens to be subjected to VMH testing was fixed in a holder with the 
Table I Composition of the materials tested as provided by the manufacturer

\begin{tabular}{|c|c|c|c|}
\hline Bulk-fill RBCs, manufacturer & Monomer/resin matrix & Fillers & Shade used \\
\hline $\begin{array}{l}\text { Tetric }{ }^{\circledR} \text { N-Ceram; Ivoclar Vivadent, } \\
\text { Schaan, Liechtenstein }\end{array}$ & DMA: 19-2।\% weight & $\begin{array}{l}\text { Barium glass, prepolymer, ytterbium } \\
\text { trifluoride, and mixed oxide }\end{array}$ & IV A \\
\hline $\begin{array}{l}\text { SonicFill }{ }^{\mathrm{TM}} \text {, nanohybrid composite } \\
\text { restorative; Kerr Corporation, Orange, } \\
\text { CA, USA }\end{array}$ & $\begin{array}{l}\text { (I-methylethylidene) bis } \\
\text { (4, I-phenyleneoxy-2, I-ethanediyloxy-2, } \\
\text { I-ethanediyl) bismethacrylate. } \\
\text { (I-methylethylidene) bis } \\
\text { [4, I-phenyleneoxy (2-hydroxy-3, } \\
\text { I-propanediyl)] bismethacrylate, } 2 \text {, } \\
\text { 2'-rthylenedioxydiethyl DMA }\end{array}$ & Glass, oxide, and silicon dioxide & $\mathrm{A} 2$ \\
\hline $\begin{array}{l}\text { SDR }{ }^{\mathrm{TM}} \text {; Dentsply Caulk, Milford, } \\
\text { DE, USA }\end{array}$ & $\begin{array}{l}\text { Modified urethane DMA resin, ethoxylated } \\
\text { bisphenol A DMA, triethylene glycol DMA }\end{array}$ & $\begin{array}{l}\text { Barium-alumino-fluoro-borosilicate glass, } \\
\text { strontium alumino-fluoro-silicate glass }\end{array}$ & $\mathrm{A} 2$ \\
\hline $\begin{array}{l}\text { Filtek }^{\mathrm{TM}} \text { Bulk Fill, posterior restorative; } \\
3 \mathrm{M} \text { ESPE, St. Paul, MN, USA }\end{array}$ & $\begin{array}{l}\text { Aromatic urethane DMA, urethane DMA, } \\
\text { and I, I2-dodecane DMA }\end{array}$ & $\begin{array}{l}\text { Non-agglomerated/non-aggregated } \\
20 \mathrm{~nm} \text { silica filler, a non-agglomerated/ } \\
\text { non-aggregated 4-II nm zirconia filler, an } \\
\text { aggregated zirconia/silica cluster filler ( } 20 \mathrm{~nm} \\
\text { silica and 4-II nm zirconia particles), and } \\
\text { a ytterbium trifluoride filler consisting of } \\
\text { agglomerate } 100 \mathrm{~nm} \text { particles }\end{array}$ & $\mathrm{A} 2$ \\
\hline
\end{tabular}

Abbreviations: DMA, dimethacrylate; RBC, resin-based composite; SDR, Smart Dentin Replacement.

test (top) surface perpendicular to the diamond indenter tip of a VMH tester (Buehler Micromet 2, Lake Bluff, IL, USA). Surface microhardness was determined by the application of a 300 ground force loaded for 15 seconds. The same machine was used to view and measure the indentation at $40 \times$ magnification. Utilizing the built-in scale and the manufacturer's conversion table, Vickers values were obtained and converted to microhardness values (Vickers hardness number, VHN). Mean values for three indentations each vertically and horizontally were calculated for all tested samples.

\section{CS and DTS tests}

The CS and DTS of 96 specimens each were determined using a universal testing machine (Instron 5965; Norwood, MA, USA) at a crosshead speed of $1 \mathrm{~mm} / \mathrm{min}$. Each specimen was positioned vertically (for CS testing) or horizontally (for DTS testing) in a specially designed jig and then placed at the base of the testing machine. A stainless steel rod (diameter, $6 \mathrm{~mm}$; length, $122 \mathrm{~mm}$ ) with a blunt surface was placed on top of the specimen, and a compressive load was applied until failure. Mean CS and DTS values (in MPa) were calculated for each RBC.

\section{Statistical analysis}

Data were expressed as mean and SD analyzed using SPSS software (version 20; IBM SPSS, Armonk, NY, USA). Paired $t$-tests were used to compare $\mathrm{VMH}$ properties among RBCs by calculating the mean values of the surfaces exposed to the two light-curing intensities. Independent sample $t$-tests were used to evaluate the CS and DTS of the RBCs exposed to the high and low light-curing intensities. One-way analysis of variance (ANOVA) and Tukey's post hoc test were used to examine the effects of high and low curing light intensities separately on the mechanical properties of the tested materials. All tests were performed at a significance level of $P<0.05$.

\section{Results \\ Microhardness}

In the total sample, regardless of curing light intensity, the highest significant values were obtained for SonicFill, followed by Filtek and Tetric N-Ceram (Table 2). Although having the least mean $\mathrm{VMH}$ values, a significant difference was observed only between SDR cured using high-intensity light compared with that cured using low-intensity light $(P<0.05)$. At low curing light intensity, the highest VMH value was obtained for SonicFill, followed by Filtek.

\section{Compressive strength}

ANOVA and post hoc tests revealed significant differences among all the materials tested, irrespective of being cured with high or low curing light intensity $(P<0.05)$. In the total sample and for high and low curing light intensities separately, the highest CS values were obtained for SonicFill, followed by SDR, and the lowest CS values were obtained for Tetric N-Ceram (Table 3 ). The CS values of all four materials cured with high-intensity light were significantly higher than those cured with low-intensity light $(P<0.05)$. 
Table 2 Mean VMH values (VHN) of the four test materials distributed according to two different curing light intensities using paired $t$-test, ANOVA, and post hoc tests

\begin{tabular}{|c|c|c|c|}
\hline Materials & $\begin{array}{l}\text { Curing } \\
\text { intensity }\end{array}$ & $\begin{array}{l}\text { VMH } \\
(\text { mean } \pm S D)^{\#}\end{array}$ & $P$-value \\
\hline \multirow[t]{2}{*}{ Filtek $^{\mathrm{TM}}$} & High & $46.36 \pm 6.05$ & 0.158 (NS) \\
\hline & Low & $49.13 \pm 2.60$ & \\
\hline \multirow[t]{2}{*}{ Tetric $^{\circledR}$ N-Ceram } & High & $39.23 \pm 3.48$ & 0.657 (NS) \\
\hline & Low & $39.63 \pm 2.03$ & \\
\hline \multirow[t]{2}{*}{ SonicFill ${ }^{\mathrm{TM}}$} & High & $58.26 \pm 4.0 \mathrm{I}$ & 0.536 (NS) \\
\hline & Low & $56.95 \pm 4.53$ & \\
\hline \multirow[t]{2}{*}{$\mathrm{SDR}^{\mathrm{TM}}$} & High & $27.27 \pm 1.86$ & $0.012^{*}$ \\
\hline & Low & $25.6 \mathrm{I} \pm \mathrm{I} .84$ & \\
\hline
\end{tabular}

Notes: $* P$-value of $<0.05$ was statistically significant; $P>0.05$ (paired $t$-test). ${ }^{* T}$ The influence of high and low light intensities was statistically significant between groups $(P<0.05)$.

Abbreviations: ANOVA, analysis of variance; NS, not significant; SD, standard deviation; SDR, Smart Dentin Replacement; VHN, Vickers hardness number; VMH, Vickers microhardness.

\section{Diametral tensile strength}

In the total sample, the highest DTS value was obtained for SDR, followed by SonicFill, and the lowest DTS value was obtained for Tetric N-Ceram (Table 3). Between high and low curing light intensities, DTS values for all RBCs except SonicFill were significant. Higher significant values were obtained among all materials cured with high curing light intensity than low curing light intensity. Multiple comparison by post hoc tests revealed that there was no significant difference among Filtek and SonicFill cured with high-intensity light. On the other hand, there were no significant differences found between Filtek and Tetric N-Ceram and also between SonicFill and SDR cured with low-intensity light $(P>0.05)$. At low curing intensity, the highest DTS value was obtained for SonicFill, followed by SDR, and the lowest DTS value was obtained for Filtek.

\section{Discussion}

The mechanical properties of restorative materials are significant indicators of success, in terms of withstanding masticatory and parafunctional forces. The mechanical properties and clinical performance of RBCs are affected by different variables. ${ }^{15}$

Microhardness is an indirect measure of the degree of conversion of a material. It provides useful information on the depth of polymerization (curing) when measured on the top and bottom surfaces of a specimen. ${ }^{16-18}$ It also indicates the material's polishability and abrasion resistance. ${ }^{19}$ In CS and DTS testing, specimens are subjected to compressive loads applied in different planes, and fracture occurs as a result of tensile and complex shear stresses. ${ }^{20}$ The CS of RBCs plays an important role in the mastication process. ${ }^{21,22}$ DTS testing was developed to investigate brittle materials with little or no plastic deformation. Low DTS may contribute to early intraoral failure of materials. ${ }^{23,24}$ The polymerization efficiency of light-cured RBCs can be assessed directly by measuring the degree of conversion and depth of cure in the laboratory. Curing efficiency, or the incremental thickness of curing through the bulk of a restoration, can be measured directly using the degree of conversion.

The depth of cure can be increased by various initiator systems incorporated in bulk-fill RBCs. ${ }^{25}$ However, one study showed that the curing depths of these composites can be lesser than those that manufacturers claim. ${ }^{26}$ Recently developed photoinitiators, including trimethylbenzoyl diphenylphosphine oxide and a dibenzoyl germanium derivative (Ivocerin; Ivoclar Vivadent, Amherst, NY, USA), were introduced as initiation boosters because of their ability to polymerize deeply and to regulate polymerization during curing of a material in bulk. ${ }^{27}$ The material may need to regulate its filler content and provide better translucency between the

Table 3 Mean CS (MPa) and DTS (MPa) of the four materials distributed according to two different curing light intensities

\begin{tabular}{|c|c|c|c|c|c|}
\hline Materials & $\begin{array}{l}\text { Curing intensity } \\
\text { ( } n=12 \text { each) }\end{array}$ & CS $(\text { mean } \pm S D)^{\#}$ & $P$-value & DTS (mean $\pm S D)$ & $P$-value \\
\hline \multirow[t]{2}{*}{ Filtek $^{\mathrm{TM}}$} & High & $235.48 \pm 3.96$ & $0.00 I^{*}$ & $75.45 \pm 2.22^{\mathrm{a}}$ & $<0.00 I^{* *}$ \\
\hline & Low & $226.92 \pm 6.64$ & & $55.13 \pm 1.42^{c}$ & \\
\hline \multirow[t]{2}{*}{ Tetric $^{\circledR}$ N-Ceram } & High & $224.06 \pm 4.89$ & $<0.001 * *$ & $63.33 \pm 1.60^{\mathrm{b}}$ & $<0.00 I^{* *}$ \\
\hline & Low & $214.28 \pm 3.67$ & & $55.57 \pm 2.40^{c}$ & \\
\hline \multirow[t]{2}{*}{ SonicFill ${ }^{\mathrm{TM}}$} & High & $262.64 \pm 3.22$ & $<0.001 * *$ & $77.69 \pm 2.65^{\mathrm{a}}$ & 0.611 (NS) \\
\hline & Low & $253.14 \pm 5.56$ & & $76.91 \pm 4.49^{d}$ & \\
\hline \multirow[t]{2}{*}{$\mathrm{SDR}^{\mathrm{TM}}$} & High & $253.19 \pm 3.90$ & $<0.001 * *$ & $86.12 \pm 3.12^{b}$ & $<0.00 I^{* *}$ \\
\hline & Low & $242.66 \pm 3.68$ & & $76.18 \pm 3.10^{d}$ & \\
\hline
\end{tabular}

Notes: $* P$-value of $<0.05$ was statistically significant; ${ }^{* * P}$-value of $<0.001$ was highly significant; $P>0.05$ (independent $t$-test); ${ }^{*} A l l$ high- and low-intensity groups were statistically significant $(P<0.05)$. DTS, all similar superscript letters were not statistically significant.

Abbreviations: CS, compressive strength; DTS, diametral tensile strength; NS, not significant; SD, standard deviation; SDR, Smart Dentin Replacement. 
filler particles and resin matrix to prevent light scattering within the material. ${ }^{27-29}$ Curing time positively affects the polymerization properties of bulk fills. Zorzin et $\mathrm{al}^{30}$ recommended enhanced light curing of bulk fills in deep and large cavities. In this study, two curing light intensities were used to examine the mechanical properties of four commercially available bulk-fill RBCs. When curing these materials, sufficient energy must be emitted to cure completely at $4 \mathrm{~mm}$ depth. The success of an RBC depends on adequate curing light exposure. ${ }^{31}$

In this study, SonicFill had the highest CS and microhardness with high and low curing light intensities. SDR had the highest DTS with high and low curing light intensities. Significant values were obtained for all materials tested, regardless of curing intensity. All materials showed optimal mechanical properties, but the DTS and microhardness values for SonicFill were not significant compared with those of the other bulk-fill RBCs. Ilie and Stark ${ }^{32}$ found that the mechanical properties of RBCs were directly proportional to filler content; they obtained the highest test values for SonicFill and Tetric EvoCeram Bulk Fill, and the SonicFill specimens showed better translucency, although the least amount of light was transmitted through them. A greater depth of cure in bulk-fill RBCs could be achieved by enhancing translucency through the reduction in filler content and increase in filler particle size. ${ }^{14}$

Didem et $\mathrm{al}^{33}$ found that SonicFill had the greatest flexural strength and CS and greater filler loading, followed by Tetric EvoCeram and SDR, which presented the lowest strength values with minimum filler content. These results are in close agreement with those of the current study. The better mechanical properties of SonicFill are attributable to its working principle; a flowable universal composite is combined with a high filled resin, which contains special modifiers that react to the energy produced by the SonicFill system. When this energy is applied via the system's handpiece, a modifier causes a reduction in viscosity, thereby increasing the flow of the composite. The composite retains a more viscous non-slumping state when the application of SonicFill energy is stopped..$^{33}$

Goodchild $^{34}$ found that SureFil SDR's patent-registered urethane dimethacrylate with photoactive groups helped to control polymerization, thereby reducing stress over the resin. This feature increases the mechanical properties of the SDR flowable material. ${ }^{35}$ In the current study, flowable SDR had the highest DTS at high and low curing light intensities. Czasch and Ilie ${ }^{36}$ compared the mechanical properties and degree of conversion of SureFil SDR Flow and Venus Bulk
Fill composites. The Venus material had a much better degree of conversion, but SDR had greater hardness and superior macromechanical properties. Increased filler content has been shown to improve the hardness and CS of RBCs. ${ }^{37}$ Bulk curing, however, produces more cumulative shrinkage than does curing in several small increments. Like other RBCs, bulk-fill RBCs work well when used with proper instruments and technique to achieve the deepest curing. ${ }^{30}$ The current study has some limitations. It was performed to evaluate the mechanical properties of bulk-fill RBCs cured at high and low intensities. Many questions on this issue come to mind, as the literature contains very little published data on bulk-fill RBC curing at different intensities. Further studies of these materials are needed to achieve their long-term success in clinical practice.

\section{Conclusion}

This study generated promising results whereby a higher curing light intensity $\left(1200 \mathrm{~mW} / \mathrm{cm}^{2}\right)$ had a positive influence on the CS and DTS of the four bulk-fill RBCs and VMH of two materials tested compared with lower curing light intensity $\left(650 \mathrm{~mW} / \mathrm{cm}^{2}\right)$. SonicFill showed the greatest VMH and CS significantly for both curing light intensities, and greater DTS with high curing light intensity, although not significant. SDR cured with high-intensity light showed the greatest DTS of the four materials. Further studies are needed to determine the optimal curing light intensity to obtain the best results in terms of mechanical properties for newer bulk-fill composite materials.

\section{Acknowledgments}

The author wishes to thank the following groups and individuals for their valuable contributions: the College of Dentistry Research Center at King Saud University for supporting this study (registration number: FR 0321); Deanship of Scientific Research at King Saud University; Nassr Al-Maflehi, Biostatistician, Department of Periodontics, College of Dentistry, King Saud University, Saudi Arabia.

\section{Disclosure}

The author reports no conflicts of interest in this work.

\section{References}

1. Leprince JG, Leveque P, Nysten B, Gallez B, Devaux J, Leloup G. New insight into the "depth of cure" of dimethacrylate-based dental composites. Dent Mater. 2012;28(5):512-520.

2. Campos EA, Ardu S, Lefever D, Jassé FF, Bortolotto T, Krejci I. Marginal adaptation of class II cavities restored with bulk-fill composites $J$ Dent. 2014;42(5):575-581.

3. Walter R. Critical appraisal: bulk-fill flowable composite resins. J Esthet Restor Dent. 2013;25(1):72-76. 
4. Ilie N, Hickel R. Investigations on a methacrylate-based flowable composite based on the SDR technology. Dent Mater. 2011;27(4):348-355.

5. Roggendorf MJ, Kramer N, Appelt A, Naumann M, Frankenberger R. Marginal quality of flowable 4-mm base vs. conventionally layered resin composite. J Dent. 2011;39(10):643-647.

6. Boaro LC, Gonçalves F, Guimarães TC, Ferracane JL, Versluis A, Braga RR. Polymerization stress, shrinkage and elastic modulus of current lowshrinkage restorative composites. Dent Mater. 2010;26(12):1144-1150.

7. Bucuta S, Ilie N. Light transmittance and micro-mechanical properties of bulk fill vs. conventional resin based composites. Clin Oral Investig. 2014;18(8):1991-2000.

8. Fan PL, Schumacher RM, Azzolin K, Geary R, Eichmiller FC. Curinglight intensity and depth of cure of resin-based composites tested according to 360 Operative Dentistry international standards. J Am Dent Assoc. 2002;133(4):429-434.

9. Al Shaafi M, Maawadh A, Al Qahtani M. Evaluation of light intensity output of QTH and LED curing devices in various governmental health institutions. Oper Dent. 2011;36(4):356-361.

10. Brandt WC, Schneider LF, Frollini E, Correr-Sobrinho L, Sinhoreti MA. Effect of different photo-initiators and light curing units on degree of conversion of composites. Braz Oral Res. 2010;24(3):263-270.

11. Li X, Pongprueksa P, Van Meerbeek B, De Munck J. Curing profile of bulk-fill resin-based composites. J Dent. 2015;43(6):664-672.

12. Leprince JG, Palin WM, Vanacker J, Sabbagh J, Devaux J, Leloup G. Physico-mechanical characteristics of commercially available bulk-fill composites. J Dent. 2014;42(8):993-1000.

13. Abouelleil H, Pradelle N, Villat C, Attik N, Colon P, Grosgogeat B. Comparison of mechanical properties of a new fiber reinforced composite and bulk filling composites. Restor Dent Endod. 2015;40(4):262-270.

14. Ilie N, Bucuta S, Draenert M. Bulk-fill resin-based composites: an in vitro assessment of their mechanical performance. Oper Dent. 2013;38(6):618-625.

15. Passos SP, Freitas AP, Jumaily S, Santos MJ, Rizkalla AS, Santos GC. Comparison of mechanical properties of five commercial dental core build-up materials. Compend Contin Educ Dent. 2013;34(1):62-68.

16. Ferracane JL. Correlation between hardness and degree of conversion during the setting reaction of unfilled dental restorative resins. Dent Mater. 1985;1(1):11-14.

17. Soh MS, Yap AU, Siow KS. The effectiveness of cure of LED and halogen curing lights at varying cavity depths. Oper Dent. 2003;28(6):707-715.

18. Aravamudhan K, Floyd CJ, Rakowski D, et al. Light-emitting diode curing light irradiance and polymerization of resin-based composite. J Am Dent Assoc. 2006;137(2):213-223.

19. Ramos MV, Frederick A, Al-Jumaily AM. Nano-filled polymer composites for biomedical applications. Proceedings of 2008 ASME International Mechanical Engineering Congress and Exposition 31 October-6 November 2008. Boston, MA, USA: American Society of Mechanical Engineers; 2008:13-17.
20. Wang L, D’Alpino PH, Lopes LG, Pereira JC. Mechanical properties of dental restorative materials: relative contribution of laboratory tests. J Appl Oral Sci. 2003;11(3):162-167.

21. Hamouda IM, Shehata SH. Fracture resistance of posterior teeth restored with modern restorative materials. J Biomed Res. 2011;25(6):418-424.

22. Atalay C, Yazici AR, Horuztepe A, Nagas E, Ertan A, Ozgunaltay G. Fracture resistance of endodontically treated teeth restored with bulk fill, bulk fill flowable, fiber-reinforced, and conventional resin composite. Oper Dent. 2016;41(5):E131-E140.

23. Della Bona A, Benetti P, Borba M, Cecchetti D. Flexural and diametral tensile strength of composite resins. Braz Oral Res. 2008;22(1):84-89.

24. Gomec Y, Dorter C, Dabanoglu A, Koray F. Effect of resin-based material combination on the compressive and the flexural strength. J Oral Rehabil. 2005;32(2):122-127.

25. Palin WM, Senyilmaz DP, Marquis PM, Shortall AC. Cure width potential for MOD resin composite molar restorations. Dent Mater. 2008; 24(8):1083-1094.

26. Garcia D, Yaman P, Dennison J, Neiva G. Polymerization shrinkage and depth of cure of bulk fill flowable composite resins. Oper Dent. 2014;39(4):441-448.

27. Moszner N, Fischer UK, Ganster B, Liska R, Rheinberger V. Benzoyl germanium derivatives as novel visible light photoinitiators for dental materials. Dent Mater. 2008;24(7):901-907.

28. Santini A. Current status of visible light activation units and the curing of light-activated resin-based composite materials. Dent Update. 2010; 37(4):214-216.

29. Alrahlah A, Silikas N, Watts DC. Post-cure depth of cure of bulk fill dental resin-composites. Dent Mater. 2014;30(2):149-154.

30. Zorzin J, Maier E, Harre S, et al. Bulk-fill resin composites: polymerization properties and extended light curing. Dent Mater. 2015;31(3): 293-301.

31. Simon JF. Success with bulk-fill composites requires understanding, attention to detail. Compend Contin Educ Dent. 2016;37(2):132-133.

32. Ilie N, Stark K. Curing behaviour of high-viscosity bulk-fill composites. J Dent. 2014;42(8):977-985.

33. Didem A, Gözde Y, Nurhan O. Comparative mechanical properties of bulk-fill resins. Open J Compos Mater. 2014;4(2):1-5.

34. Goodchild JH. Why use bulk-fill flowable composites? Inside Dent. 2013;9(8):92-95.

35. Jang JH, Park SH, Hwang IN. Polymerization shrinkage and depth of cure of bulk-fill resin composites and highly filled flowable resin. Oper Dent. 2015;40(2):172-180.

36. Czasch P, Ilie N. In vitro comparison of mechanical properties and degree of cure of bulk fill composites. Clin Oral Investig. 2013;17(1):227-235.

37. Marigo L, Spagnuolo G, Malara FO, et al. Relation between conversion degree and cytotoxicity of a flowable bulk-fill and three conventional flowable resin-composites. Eur Rev Med Pharmacol Sci. 2015; 19(23):4469-4480.
Clinical, Cosmetic and Investigational Dentistry

\section{Publish your work in this journal}

Clinical, Cosmetic and Investigational Dentistry is an international, peer-reviewed, open access, online journal focusing on the latest clinical and experimental research in dentistry with specific emphasis on cosmetic interventions. Innovative developments in dental materials, techniques and devices that improve outcomes and patient satisfac-
Dovepress

tion and preference will be highlighted. The manuscript management system is completely online and includes a very quick and fair peerreview system, which is all easy to use. Visit http://www.dovepress. com/testimonials.php to read real quotes from published authors. 